\title{
Variation in Bacterial and Eukaryotic Communities Associated with Natural and Managed Wild Blueberry Habitats
}

Svetlana N. Yurgel, ${ }^{\dagger}$ Department of Plant, Food, and Environmental Sciences, Dalhousie University, Truro, NS, Canada; Gavin M. Douglas, Department of Microbiology and Immunology, Dalhousie University, Halifax, NS, Canada; André M. Comeau, CGEB-Integrated Microbiome Resource (IMR) and Department of Pharmacology, Dalhousie University, Halifax, NS, Canada; Melissa Mammoliti, Ashley Dusault, and David Percival, Department of Plant, Food, and Environmental Sciences, Dalhousie University, Truro, NS, Canada; and Morgan G. I. Langille, CGEB-IMR and Department of Pharmacology, Dalhousie University, Halifax, NS, Canada

Accepted for publication 21 June 2017.

\section{ABSTRACT}

We examined the differences between bacterial and eukaryotic soil communities associated with natural and managed habitats of wild blueberry, Vaccinium angustifolium. In total, 138 bacterial and 130 eukaryotic soil and rhizosphere communities across seven blueberry fields, all established at least 30 years ago and from two forest areas adjacent to some of these fields, were analyzed. We analyzed correlations between soil chemical factors and the structure of eukaryotic and bacterial communities, including differences in the microbiome between bulk and rhizosphere soils, and between rhizospheres of plants growing in natural and managed habitats. Characterization of a broad selection of fields across the province of Nova Scotia, Canada, allowed us to tentatively identify specific signatures from several distinct soil niches. Our data indicate that bacterial and eukaryotic communities differ in how they correlate with soil chemical properties. Also, while eukaryotic communities correlate stronger with soil fertility than bacterial communities, plant selection had a stronger effect on bacterial microbiomes than on eukaryote microbiomes. Additionally, we found that the composition of rootassociated bacterial communities differs between managed and natural wild blueberry habitats, confirming previous reports that management can affect rhizosphere microbiomes.
The importance of the soil microbiome for plant function is a wellknown concept (Lareen et al. 2016). Plant and soil microbes are now considered to be ecological units, with multilevel interactions occurring between plants, microbial communities, and the soil (Philippot et al. 2013). Moreover, soil microbiomes are the essential components of the entire plant ecosystem, the phytobiome, and the diversity and structure of microbial communities can be influenced by abiotic environmental factors and by biotic interactions encompassing the plant community, other microbes, and the soil organisms, including the microfauna. These influences affect growth, survival, differential selection, and dispersion in both deterministic and stochastic ways (Fisher and Mehta 2014; Maignien et al. 2014; Morrison-Whittle and Goddard 2015). Plantassociated microbiomes can have adverse, neutral or beneficial effects on host health and development (Berendsen et al. 2012; MorrisonWhittle and Goddard 2015; Panke-Buisse et al. 2015). In return, host

${ }^{\dagger}$ Corresponding author: S. N. Yurgel; E-mail: syurgel@dal.ca

*The $e$-Xtra logo stands for "electronic extra" and indicates that four supplementary tables and seven supplementary figures are published online.

(C) 2017 The American Phytopathological Society plants manipulate their associated microbiomes, providing selective environments in their rhizospheres by releasing exudates, whose composition reflects host genotype, age, developmental stage, nutritional needs, and environmental stresses (Chaparro et al. 2014; Lareen et al. 2016; Micallef et al. 2009a, b; Reinhold-Hurek et al. 2015; Tkacz et al. 2015). These selective environments shape rhizosphere microbiomes and lead to differences in microbial community composition and structure between bulk soil and the rhizosphere. Additionally, bacterial and eukaryotic communities can respond differently to this plant selective pressure as they compete for nutrients and plant root colonization (Lareen et al. 2016).

Due to a significant gap between simplified experimental laboratory conditions and the complex environments where holobionts exist in nature, translating a basic understanding of plant-microbiome interactions to natural and managed ecosystems is nontrivial. With a few small exceptions, most agricultural practices involve introducing an exogenous crop into a pre-existing or newly established ecosystem, crop rotation or tillage. These systems do not necessarily reflect plantmicrobiome interactions that occur in natural habitats. Moreover, "soil memory," where a predecessor holobiont can generate a long-lasting effect on the soil microbiome, can influence adaptability of the newly introduced plant lines to the environment (Donn et al. 2015; Lapsansky 
et al. 2016; Quadros et al. 2012) and complicate our understanding of plant-microbiome interactions in natural and managed ecosystems. Soil physiochemical properties can also affect the composition of microbial communities in bulk soils and serve as boundary conditions for shaping rhizosphere microbiomes (Tkacz et al. 2015).

Most amplicon sequencing analyses of the factors shaping soil microbiomes, as well as the analyses of the effect of plant selection on rhizosphere communities have focused on bacterial and fungal populations. In contrast to the progress in our understanding of eukaryotic diversity in aquatic systems (Caron et al. 2012), limited information exists on the response of microbes other than fungal soil eukaryotes to environmental factors and even less is known about the effects of plant selection on these organisms. In this study, we used wild blueberry, Vaccinium angustifolium, in various production system environments to evaluate the differences between bacterial and eukaryotic soil communities associated with natural and managed habitats as well as the differences between microbial communities in bulk soil and the rhizosphere.

Wild blueberry is a crop native to North America. Over the years, commercial management of native blueberry stands was designed to maintain field conditions close to a "natural" state, including development of fields on deforested land by removing competing vegetation from native wild blueberry stands (Bell et al. 2009; Drummond et al. 2009; Eaton 1988; Hall et al. 1979). In contrast to agricultural systems where the crop replaces what has come before, each blueberry field develops from a native ecosystem with relatively undisturbed soil properties, existing plant species and microbial communities. The lack of barriers between fields and surrounding areas enables constant mixing of microbial species. Fields typically have a high proportion of weed patches and bare spots, permanent patches without vegetation cover (Percival and Privé 2002). Most of the soils in blueberry production in Canada are infertile and acidic with $\mathrm{pH}$ ranging from 4.5 to 5.5 (Korcak 1989), to which wild blueberries are well adapted. Part of this adaptation is based on the development of an extensive root and rhizome system and establishment of beneficial interactions with soil microbes, including bacteria and fungi (Goulart et al. 1993). For example, as part of the wild blueberry phytobiome, ericoid mycorrhizae mainly represented by Ascomycota (van der Heijden et al. 2015), play an important role in wild blueberry adaptation to low fertility soils, promoting uptake of nitrogen and phosphorus and improving plant tolerance of dry conditions (Jeliazkova and Percival 2002; Read 1983; Wilson 1908). Wild blueberry management follows a 2-year production cycle, with a vegetative (i.e., sprout) year and a crop year. Bushes are pruned after fruit is harvested in late fall of a crop year (Hall et al. 1979). Application of granular, soil-applied fertilizers is limited to the sprout year with $\sim 26$ to $32 \mathrm{~kg} / \mathrm{ha}$ of a 16-304 fertilizer typically being applied. During a crop year, fungicides, such as propiconazole, fludioxonil, cyprodonil, boscalid, and cyprodonil, may be applied to control Monilinia blight, Botrytis blossom blight and Septoria leaf spot.

A recent study showed that the shift in land-use from forest to cropland or pasture generally alters the structure and composition of microbial communities (Mendes et al. 2015). Development and management of wild blueberry fields changes plant growth conditions by removing competing vegetation, using soil or plant applied fertilizers, herbicides and fungicides, and plant pruning. However, during a blueberry crop production year no fertilizers or herbicides are applied to the fields and plants are fully recovered from pruning. Consequently, this stage of management of blueberry fields provides a powerful baseline for evaluating plant-microbiome responses to relatively minor land-use changes. In this study, we analyzed wild blueberry phytobiomes from forests and adjacent managed fields, focusing specifically on soil by evaluating soil chemical properties and bacterial and eukaryotic communities in relation to soil chemical properties. This work sheds light on variation in blueberry bacterial and eukaryotic soil microbiomes across the landscape, and shows differences in responsiveness of bacterial and eukaryotic microbiomes to biotic (plant presence or absence) versus abiotic (soil chemical characteristics) factors in soil.

\section{MATERIALS AND METHODS}

Sample collection soil processing and DNA extraction. Samples were collected across seven managed blueberry fields and two forest sites adjacent to Dalhousie University Research Centre fields at Debert and Collingwood in Nova Scotia, Canada (Supplementary Fig. S1; Supplementary Tables S1 and S2). Samples were collected from six niches: (i) bulk soil closely associated with blueberry plants within managed fields (MngBulk); (ii) soil from bare spots within managed fields (MngBare); (iii) rhizosphere of wild blueberry plants within managed fields (MngRhizo); (iv) forest soils distant from blueberry plants (FrstCtr); (v) forest soils closely associated with wild blueberry (FrstBulk); and (vi) rhizosphere of forest grown blueberry (FrstRhizo). All the sampling sites had similar sandy, well-drained acidic soils. Samples were collected from the fields during the second year of a crop production year in August 2015, approximately 2 weeks before harvest.

Bulk field soil (MngBulk) samples (500 g) were taken from the top $20 \mathrm{~cm}$ topsoil layer from directly under blueberry plants in an $\mathrm{X}$-shaped pattern with at least $30 \mathrm{~m}$ of distance between each collection point creating a total of five collection points in each sampling site and a total of 40 samples. Each field had one sampling site, except for Debert-1, which had two. The litter layer was removed, plant material samples were sieved $(5 \mathrm{~mm})$, placed in sterile bags, transported into the laboratory on ice, and immediately stored at $-20^{\circ} \mathrm{C}$ for chemical characterization. After transportation to the lab, $5 \mathrm{~g}$ of the soil samples was sieved $(2 \mathrm{~mm})$ and immediately stored at $-86^{\circ} \mathrm{C}$ until processing for DNA isolation. DNA was isolated from $0.25 \mathrm{~g}$ of soil.

Rhizosphere (MngRhizo) samples were taken from the plants located in MngBulk sampling points, five collection points in each sampling site, for a total of 35 samples. Wild blueberry rhizomes and associated roots were extracted from soils, vigorously shaken, placed in sterile bags, and transported to the laboratory on ice. Root samples were processed immediately after transportation to the laboratory. Blueberry roots were placed in a Falcon tube $(50 \mathrm{ml})$ with $10 \%$ glycerol $(40 \mathrm{ml})$ and vortexed until adhering soil had been visibly removed from the root. The roots were removed and the soil suspension was centrifuged at 3,000 $\times g$ for $15 \mathrm{~min}$. The supernatant was decanted, and the soil pellets were transferred into 1.5-ml Eppendorf tubes and stored at $-86^{\circ} \mathrm{C}$. DNA was isolated from $0.25 \mathrm{~g}$ (wet weight) of rhizosphere soil. The preparation of rhizosphere samples did not include ultrasound treatment of roots, which eliminated most rhizoplane and endophytic populations.

Bare spots (MngBare) samples (500 g) were taken from managed fields by collecting the top $20 \mathrm{~cm}$ topsoil layer within random permanent patches that lacked vegetation cover, five sampling points in each site, for a total of 15 samples. The samples were processed like the MngBulk samples.

Bulk forest soils (FrstBulk) samples (500 g) were taken from the top $20 \mathrm{~cm}$ topsoil layer from directly under blueberry plants, which were chosen randomly in the forest area near managed fields used for MngBulk, MngBare, and MngRhizo sampling. In most cases, the development of managed fields had completely removed adjacent forest areas. Consequently, only two forest areas were used for sampling. A total of 20 samples were collected. The samples were processed like the MngBulk samples.

Forest rhizosphere (FrstRhizo) samples were taken from the plants located in FrstBulk sampling points, 15 samples total, and processed like the MngRhizo samples. 
Forest control (FrstCtr) samples (20 samples) were taken randomly from the area with no blueberry plant present within at least $1 \mathrm{~m}$ and processed like the MngBulk samples.

Soil chemical parameters. Soil chemical parameters were determined for all MngBulk, MngBare, FrstBulk, and FrstCtr samples at the Nova Scotia Department of Agriculture \& Food Operations Laboratory Services (Harlow Institute). Each soil sample was characterized by determining $\mathrm{pH}$, total nitrogen $(\mathrm{N}, \%)$, organic matter $(\mathrm{OM}, \%), \mathrm{P}_{2} \mathrm{O}_{5}$ (kg/ha), $\mathrm{K}_{2} \mathrm{O}$ (kg/ha), Ca (kg/ha), Mg (kg/ha), Na (kg/ha), S (kg/ha), Fe (ppm), $\mathrm{Mn}$ (ppm), $\mathrm{Cu}$ (ppm), Zn (ppm), $\mathrm{Al}$ (ppm), and cation-exchange capacity (CEC, meq/100 g) according to standard procedures (Goldin 1987; Mehlich 1984).

DNA extraction and sequencing. DNA extraction was carried out using the PowerSoil DNA Isolation Kit (MO BIO Laboratories, Carlsbad, CA) according to the manufacturer's protocol. DNA quality and concentration were measured using a NanoDrop 1000 spectrophotometer (Thermo Scientific, Waltham). Five microliters of DNA sample was sent to the Dalhousie University CGEB-IMR (http://cgebimr.ca/) for V6-V8 16S rRNA gene (16S) and V4 18S rRNA gene (18S) library preparation and sequencing. Samples were multiplexed using a dual-indexing approach and sequenced using an Illumina MiSeq with paired-end $300+300 \mathrm{bp}$ reads. All PCR procedures, primers, and Illumina sequencing details were as described in Comeau et al. (2017).

Sequencing data processing. We used the Microbiome Helper standard operating procedure to process and analyze the sequencing data (Comeau et al. 2017). Briefly, overlapping paired-end reads were stitched together using PEAR (v0.9.6) (Zhang et al. 2014a, b). A total of 98.3 and $78.9 \%$ of the $16 \mathrm{~S}$ and $18 \mathrm{~S}$ reads were successfully stitched, respectively. We then ran FASTX-Toolkit (v0.0.14) (Gordon and Hannon 2010) to filter out reads that had a quality score less than 30 at $>10 \%$ of positions. In addition, we filtered out reads shorter than 400 bp that did not contain matching $5^{\prime}$ and $3^{\prime}$ sequences to the appropriate forward and reverse primers with BBMap (v35.85) (Bushnell 2014). Lastly, we ran USEARCH (v6.1) (Bushnell 2014; Edgar et al. 2011) to screen out chimeric reads using the options mindiv $=1.5$ and $\operatorname{minh}=0.2$.

Operational taxonomic unit (OTU) picking and statistical analyses. Following these filtering steps, we ran open-reference OTU picking using QIIME wrapper scripts (Caporaso et al. 2010). Specifically, SortMeRNA (v2.0-dev) (Kopylova et al. 2012) was used for the reference OTU picking steps (with sortmerna_coverage $=0.8$ ) and sumaclust (v1.0.00) (Mercier et al. 2013) for the de novo OTU picking steps (with $10 \%$ of the failures subsampled). We filtered out OTUs that contained fewer than $0.1 \%$ of the total sequences in order to compensate for MiSeq run-to-run bleed-through (Comeau et al. 2017). With these OTU tables in hand, we took two main approaches to identify associations of sample groupings and chemical factors to the community structures. Firstly, we tested for associations between these variables and the sample distance matrix for both the $16 \mathrm{~S}$ and $18 \mathrm{~S}$ datasets. This approach identifies whether the variables of interest are associated with community structure in general. The second approach is to identify individual taxa whose relative abundances are associated with these variables. We then generated alpha-diversity (richness and Chao1) and beta-diversity (weighted UniFrac distance) (Lozupone et al. 2011) metrics using QIIME. We used the "cca" function from the R package vegan (v2.4-0) (Oksanen et al. 2016) to run the canonical correspondence analyses (CCAs). Spearman and Tukey's pairwise tests were run using the Past3 package (Hammer et al. 2001). Adonis tests (999 permutations) were run in QIIME to calculate how sample groupings and soil chemical factors are related to microbial community structure. These tests are a measure of how much variation in community structure is explained by the variable of interest. Pairwise Spearman correlations between factors was performed using the "rcorr" function of the Hmisc R package (http://biostat.mc.vanderbilt.edu/wiki/ Main/Hmisc). To test for fungi that have differential abundance across metadata categories, the $18 \mathrm{~S}$ BIOM table was parsed to contain only fungal OTUs. Analysis of taxonomic profiles was performed using the STAMP software package (Parks et al. 2014). All sequences generated in this study are available in the NCBI sequence read archive under the accession numbers PRJNA389786 (16S rRNA) and PRJNA391782 (18S rRNA).

\section{RESULTS}

Composition of microbial communities across all environmental samples. Eukaryotic communities. After the first round of sequencing, 5 out of 145 samples had low quality and a second round of DNA isolation and sequencing did not improve the dataset. These samples were removed from the analysis. A total of 1,971,195 high-quality $18 \mathrm{~S}$ sequences were obtained from remaining samples. After normalization to a depth of 3,378 reads (the depth of the smallest dataset after the 10 lowest samples were removed), 439,140 reads were retained. These reads were distributed among 8,137 OTUs across 6 datasets comprising 130 samples at $99 \%$ identity. About 14, 19, and $35 \%$ of all reads were classified as Rhizaria, Alveolates, and Opisthokonts, respectively. Kingdom Archaeplastida/Plantae (458 OTUs) was mostly represented by the division of Embryophyta (395 OTUs). Around $23 \%$ of the total OTUs (1,648 OTUs, 128,579 reads), which were part of Opisthokonts division, were classified as fungi (Table 1). The most relatively abundant fungal phylum was Ascomycota followed by Mucoromycota and Basidiomycota, represented by 21, 2, and $1 \%$ of all identified fungal OTUs, respectively. The most common fungal classes were Archaeorhizomycetes, Lipomycetaceae, Stephanoascales, Agaricomycetes, Dothideomycetes, and Eurotiomycetes, representing $\sim 5$ to $11 \%$ of all identified fungal OTUs. In addition to Rhizaria, Alveolates, and Opisthokonts, the top 15 most relatively abundant eukaryotes (Table 1), representing $\sim 79 \%$ of all identified eukaryotes, also included Hacrobia groups.

Four eukaryotic groups identified in this study, Hacrobia/ Prymnesiophyceae, Hacrobia/Telonemia, Metazoa/Urochordata, and Rhizaria/Acantharea, do not appear to have been reported in soils before, but have been found in aquatic environments (Supplementary Table S3). An indication that the presence of these species was not the result of contamination was that these groups were relatively abundant, representing between 5\% (Urochordata) and 2\% (Telonemia) of total normalized reads (Table 1 ). To verify the validity of the taxonomic assignments, we manually annotated OTUs (BLASTn) from each group (106 OTUs total) and all but one OTU (JN816839.1.934_U) was confirmed to be from aquatic-related eukaryotes.

Bacterial communities. A total of 3,621,053 high-quality $16 \mathrm{~S}$ sequences were obtained from 145 samples. Seven samples were removed from the analysis due to low sequencing depth and the remaining samples were normalized to a depth of 15,943 reads. The remaining 2,184,191 reads were distributed between 8,904 OTUs at $97 \%$ identity. Altogether, the top 15 most relatively abundant bacterial taxa, which included classes of Acidobacteria, Actinobacteria, Alpha-, Beta-, Delta- and Gammaproteobacteria, Chloroflexi, Bacteroidetes, Verrucomicrobia, and candidate divisions WPS-2 and AD3 (Table 1), represented $\sim 85 \%$ of all identified bacteria. Acidobacteria, including DA052 and Solibacteres, and Alphaproteobacteria were dominant bacterial classes and accounted for $\sim 36$ and $13 \%$ of all identified OTUs, respectively.

Diversity of soil microbial communities. We visualized dissimilarity between microbial communities from a variety of environmental samples using principal coordinate analysis (PCoA) (Supplementary Fig. S2). In contrast to bacteria, eukaryotic 
communities were clearly separated into two clusters. The analysis of strength and statistical significance of sample groupings (Adonis test) indicated that, while sample type (FrstCtr, FrstBulk, FrstRhizo, MngBulk, MngRhizo, and MngBare) influenced the structure of the eukaryotic community $\left(R^{2}=0.15, P<0.001\right)$, sampling site (all types of samples from a single location) had a stronger effect on soil eukaryotes $\left(R^{2}=0.34, P<0.001\right)$ (Table 2$)$. On the other hand, site had less effect on the structure of bacterial communities $\left(R^{2}=0.22\right.$, $P<0.001)$, which was comparable to the effect of the sample type $\left(R^{2}=0.27, P<0.001\right)$. Grouping by management type (i.e., forest versus managed fields) showed the weakest effects: $R^{2}=0.06$ and $R^{2}=0.09$ for eukaryotic and bacterial communities, respectively, but was statistically significant for both groups of microorganisms $(P<0.001)$.

The correlation between soil properties and the structure of eukaryotic communities from managed blueberry fields. We used canonical correspondence analysis (CCA) to explore the link between soil factors and differences in OTUs across managed samples (Fig. 1). While CCA considers individual soil characteristics as independent factors, the possibility that some of these factors might be associated and not independent should not be dismissed (Supplementary Fig. S3). Eukaryotic communities from managed fields formed two distinct clusters, each containing both sample types (MngBare and MngBulk) (Fig. 1). One cluster contained both MngBulk and MngBare sample types from Farmington, Collinwood, and Debert-2, herein referred to as Group I fields (Supplementary Fig. S4). The second cluster contained samples from fields: DBRC, NSBI, Debert-1, and Mt. Thom, herein referred to as Group II fields. The forest samples were combined as Group III. Grouping eukaryotic communities into these Group I and II fields explained a significant amount of variation in eukaryotic community structure (Adonis $R^{2}=0.20, P<$ 0.001) (Table 2). This became more apparent by comparing CCA plots with sample groupings by sample type (MngBare versus

TABLE 1

Correlation analysis considering the top 15 most abundant eukaryotes and bacteria, and chemical soil factors ${ }^{2}$

\begin{tabular}{|c|c|c|c|c|c|c|c|c|c|c|}
\hline Taxon & Abundance & $\mathrm{pH}$ & Total $\mathrm{N}$ & Organic matter & CEC & $\mathrm{P}_{2} \mathrm{O}_{5}$ & Sulfur & $\mathrm{Mg}$ & $\mathrm{K}_{2} \mathrm{O}$ & $\mathrm{Al}$ \\
\hline Fungi, Ascomycota & $21 \%$ & $0.229^{*}$ & $-0.355^{\star \star}$ & $-0.382^{\star \star}$ & $-0.390^{\star *}$ & -0.157 & 0.005 & -0.171 & 0.006 & 0.062 \\
\hline Alveolata, Dinophyceae & $10 \%$ & -0.190 & $0.364^{* *}$ & $0.389^{\star *}$ & $0.420^{\star *}$ & 0.176 & -0.153 & $0.265^{\star}$ & 0.040 & -0.061 \\
\hline Metazoa, Urochordata & $5 \%$ & -0.166 & $0.326^{* *}$ & $0.351^{\star \star}$ & $0.388^{* *}$ & 0.192 & -0.145 & $0.255^{*}$ & 0.035 & -0.061 \\
\hline Rhizaria, Acantharea & $3 \%$ & -0.198 & $0.367^{* *}$ & $0.401^{\star *}$ & $0.441^{* *}$ & 0.221 & -0.153 & $0.279^{* *}$ & 0.055 & -0.073 \\
\hline Filosa-Sarcomonadea & $3 \%$ & $0.409^{\star \star}$ & $-0.452^{\star \star}$ & $-0.454^{\star \star}$ & $-0.492^{\star \star}$ & $-0.205^{\star *}$ & $0.248^{\star \star}$ & $-0.387^{\star \star}$ & $-0.180^{* *}$ & $0.404^{\star \star}$ \\
\hline Metazoa, Rotifera & $2 \%$ & -0.133 & 0.077 & 0.006 & -0.119 & 0.153 & 0.079 & -0.105 & 0.082 & -0.201 \\
\hline Animalia, Nematoda & $2 \%$ & 0.215 & -0.126 & -0.155 & -0.221 & 0.044 & -0.164 & 0.093 & 0.144 & 0.039 \\
\hline Fungi, Basidiomycota & $1 \%$ & 0.194 & $-0.342^{\star *}$ & $-0.335^{\star \star}$ & $-0.275^{\star}$ & -0.067 & 0.053 & 0.012 & 0.209 & 0.095 \\
\hline Animalia, Annelida & $1 \%$ & -0.050 & 0.138 & 0.176 & 0.190 & 0.048 & -0.121 & 0.217 & $0.252^{*}$ & -0.010 \\
\hline \multicolumn{11}{|l|}{ Bacteria } \\
\hline Acidobacteria, DA052 & $16 \%$ & -0.206 & -0.153 & -0.091 & -0.021 & $-0.371^{\star \star}$ & 0.079 & $-0.267^{\star}$ & $-0.452^{\star \star}$ & -0.081 \\
\hline Acidobacteria & $13 \%$ & $-0.534^{\star *}$ & $0.532^{\star \star}$ & $0.481^{\star *}$ & $0.368^{\star *}$ & $0.438^{\star *}$ & $-0.371^{\star *}$ & $0.560^{\star \star}$ & $0.418^{\star \star}$ & $-0.611^{\star *}$ \\
\hline Alphaproteobacteria & $13 \%$ & -0.131 & 0.172 & 0.201 & $0.255^{\star}$ & $0.229^{*}$ & $-0.403^{\star \star}$ & $0.459^{\star \star}$ & $0.421^{\star \star}$ & -0.210 \\
\hline Acidobacteria, Solibacteres & $7 \%$ & -0.096 & 0.140 & 0.115 & 0.060 & 0.173 & $-0.502^{\star \star}$ & $0.339^{*}$ & 0.123 & $-0.390^{* *}$ \\
\hline Verrucomicrobia, Spartobacteria & $5 \%$ & $0.227^{*}$ & -0.230 & -0.207 & -0.143 & -0.004 & $0.267^{*}$ & -0.159 & 0.071 & $0.272^{*}$ \\
\hline Deltaproteobacteria & $5 \%$ & 0.135 & -0.166 & -0.132 & -0.119 & $-0.390^{\star \star}$ & $-0.251^{*}$ & -0.050 & $-0.309^{\star *}$ & 0.006 \\
\hline Candidate division WPS-2 & $2 \%$ & -0.045 & -0.025 & -0.065 & -0.060 & -0.082 & $0.539^{* *}$ & $-0.420^{\star *}$ & $-0.233^{*}$ & 0.194 \\
\hline Verrucomicrobia, Pedosphaerae & $2 \%$ & -0.089 & $0.246^{*}$ & 0.231 & $0.219^{*}$ & 0.206 & $-0.465^{\star *}$ & $0.503^{\star *}$ & $0.284^{*}$ & $-0.361^{* *}$ \\
\hline Actinobacteria, Thermoleophilia & $2 \%$ & 0.108 & 0.186 & 0.195 & 0.213 & 0.212 & 0.100 & 0.180 & $0.443^{\star *}$ & $0.255^{\star}$ \\
\hline
\end{tabular}

z Spearman's rank correlation test. Significance levels are shown at ${ }^{\star} P<0.05,{ }^{\star \star} P<0.01$, and ${ }^{\star \star \star} P<0.001$. 
MngBulk) (Fig. 1A) or by groups (Group I versus Group II) (Fig. 1B).

Pairwise comparisons of Chao1 richness, and Simpson evenness revealed significant differences between Group I and Group II fields in eukaryotic alpha-diversity. Eukaryotic communities from Group I fields exhibited higher richness, and evenness, compared with Group II fields, while no significant differences in these parameters were detected between MngBulk and MngBare (Fig. 2). CCA indicated that there is a correlation between the structure of the eukaryotic communities and soil $\mathrm{N}, \mathrm{S}, \mathrm{OM}, \mathrm{P}_{2} \mathrm{O}_{5}$, and CEC (Fig. 1A). In agreement with this conclusion, the soils from Group I and II fields differed significantly in all these characteristics (Table 3), with soils from Group I fields having higher amounts of N, OM,
$\mathrm{P}_{2} \mathrm{O}_{5}$, and CEC and lower amounts of $\mathrm{S}$ than the soils from Group II. On the other hand, $\mathrm{N}, \mathrm{OM}, \mathrm{P}_{2} \mathrm{O}_{5}$, and $\mathrm{CEC}$ amounts did not differ between MngBulk and MngBare soils. Moderate, but significant, correlation between eukaryotic richness, diversity and community structure and soil N, OM, and CEC was observed (Table 4; Supplementary Table S4). The relative abundances of 11 eukaryotic groups, representing $\sim 70 \%$ of total 18 S OTUs and belonging to the top 15 most relatively abundant eukaryotes identified in this study, were correlated with $\mathrm{N}, \mathrm{OM}$, and CEC (Table 1). These findings suggest that there is a correlation between N, OM, and CEC and structure of eukaryotic communities in the managed fields.

Considering taxonomic groups, 12 out of the top 15 most relatively abundant eukaryotes varied significantly over groups of the

TABLE 2

Variation in sample groupings explained by weighted UniFrac beta-diversity distances

\begin{tabular}{|c|c|c|}
\hline Grouping (subset) ${ }^{\mathrm{y}}$ & $18 \mathrm{~S}\left(R^{2}\right)$ & $16 \mathrm{~S}\left(R^{2}\right)$ \\
\hline Site location (all samples) & $0.3399^{\star \star \star}$ & $0.22179^{\star \star \star}$ \\
\hline Sample type (MngBare, MngBulk) & 0.03198 & $0.13067^{* * *}$ \\
\hline Group I, II (MngBare, MngBulk) & $0.2034^{\star \star \star}$ & $0.07865^{\star \star \star}$ \\
\hline Sample type (MngBulk/FrstBulk, MngRhizo/FrstRhizo) $^{z}$ & $0.02594^{\star}$ & $0.10694^{\star \star \star}$ \\
\hline Sample type (Group I; MngBulk, MngRhizo) & $0.12123^{\star}$ & $0.14237^{\star \star}$ \\
\hline Sample type (Group II; MngBulk, MngRhizo) & $0.04968^{*}$ & $0.10755^{\star *}$ \\
\hline Sample type (Group III; FrstBulk, FrstRhizo) & $0.07719^{*}$ & $0.19737^{\star \star \star}$ \\
\hline Sample type (MngRhizo, FrstRhizo) & $0.06896^{\star}$ & $0.22225^{\star \star *}$ \\
\hline
\end{tabular}
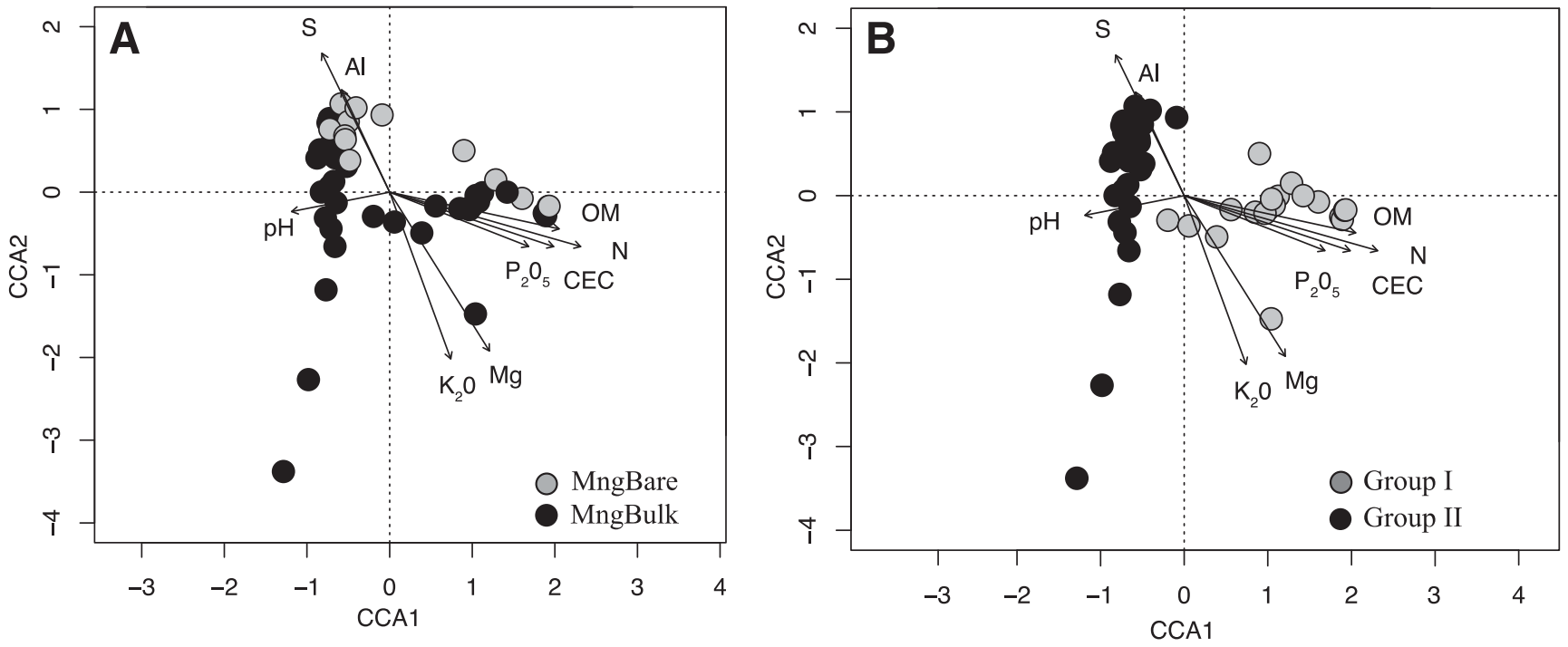

Fig. 1. Canonical correspondence analysis (CCA) used to determine which factors are linked to differences in eukaryotic OTUs across samples from bulk soil (MngBulk) and bare spots (MngBare) from managed fields. The rarified OTU table was used as input for the 18S amplicon data. A, Samples were grouped by sample type: bulk soils (MngBulk) and bare spots (MngBare). B, Samples were grouped by field types: Group I and Group II fields. N, nitrogen; OM, organic matter; CEC, cation-exchange capacity (number of exchangeable cations per dry weight of soil); $\mathrm{P}_{2} \mathrm{O}_{5}$, phosphate; $\mathrm{K}_{2} \mathrm{O}$, potassium; Mg, magnesium; S, sulfur; and Al, aluminum. 
fields (Fig. 3A; Supplementary Fig. S5), but not between MngBulk and MngBare. Fungi, Ascomycota, Basidiomycota, and Mucoromycota, Metazoa/Rotifera, Archaeplastida/Embryophyceae, and Rhizaria/ Filosa-Sarcomonadea were relatively more abundant in Group II fields. Most Prymnesiophyceae, Telonemia, Urochordata, and Acantharea OTUs were found in Group I field and forest samples (Fig. 3A). We could not attribute the presence of these groups to the specific location of the sampling sites, since one forest sampling site was close to the field from Group I (Collingwood) and a second one was close to the fields from Group II (DBRC and NSBI). Additionally, two fields, Debert-1 and Debert-2, belonging to Group II and Group I, respectively, are in close proximity to each other. These results agreed with correlations of taxonomic relative abundances with abiotic composition. The relative abundances of Ascomycota, Mucoromycota, Embryophyceae, and Filosa-Sarcomonadea were negatively correlated, while the relative abundances of Hacrobia, Dinophyceae, Rhizaria, and Metazoa were positively correlated with $\mathrm{N}$, OM, and CEC (Table 1).

The correlation between soil properties and the structure of bacterial communities from managed blueberry fields. In contrast to eukaryotes, grouping of soil bacterial communities by Group I and II fields showed a weaker correlation $\left(R^{2}=0.08, P<0.01\right)$, compared with grouping by sample types, MngBare and $\operatorname{MngBulk}\left(R^{2}=\right.$ $0.13, P<0.001$ ) (Table 2). Individual soil chemical characteristics correlated with relative abundances of many bacterial classes. Relative abundances of 11 ( $\sim 72 \%$ of total OTUs), 12 ( $\sim 66 \%$ of total OTUs), and 11 (65\% of total OTUs) bacterial classes belonging to the top 15 most relatively abundant bacteria identified in this study were correlated with $\mathrm{Mg}, \mathrm{S}$, and $\mathrm{K}_{2} \mathrm{O}$, respectively (Table 1 ). Soil fertility parameters exhibited less correlation with bacterial relative abundances: N, OM, and CEC correlated with 18,27 , and $42 \%$ of total OTUs, respectively. CCA (Fig. 4A and B) and Adonis tests also detected a correlation between individual soil chemical parameters and the OTU structure of bacterial communities. According to the Adonis test, soil $\mathrm{pH}$ and concentrations of $\mathrm{Al}$ and $\mathrm{Mg}$ were the most important variables affecting bacterial community structure. Considering taxonomic groups, Acidobacteria, Beta- and Gammaproteobacteria were relatively more abundant and Acidobacteria DA052 and candidate division ABS-6 were relatively less abundant in Group I fields (Supplementary Fig. S6). Ktedonobacteria and candidate division WPS-2 were relatively more abundant and Spartobacteria and Alpha- and Gammaproteobacteria were relatively less abundant in MngBare than in MngBulk (Fig. 3B). However, no significant differences in bacterial richness and evenness between Group I and Group II fields, nor between MngBulk and MngBare, were detected (Fig. 2). This data suggested that, while individual soil chemical characteristics correlated with the composition of soil bacteria, the overall structure of the bacterial communities was not strongly affected by the combined effects of these factors.

The correlation between soil properties and the structure of forest microbial communities. Sample type (FrstBulk versus FrstCtr) was a significant factor for grouping forest eukaryotic communities $\left(R^{2}=0.22, P<0.01\right)$ (Table 2; Fig. 5A). CCA indicated stronger correlation between the structure of the eukaryotic communities and soil $\mathrm{pH}, \mathrm{Al}, \mathrm{S}$, and CEC compared with other soil characteristics (Fig. $5 \mathrm{~A}$ ). No differences in the amounts of N, OM, and CEC were detected between FrstBulk and FrstCtr, but $\mathrm{Al}$ content and $\mathrm{pH}$ were lower in FrstBulk compared with FrstCtr (Table 3). Several studies
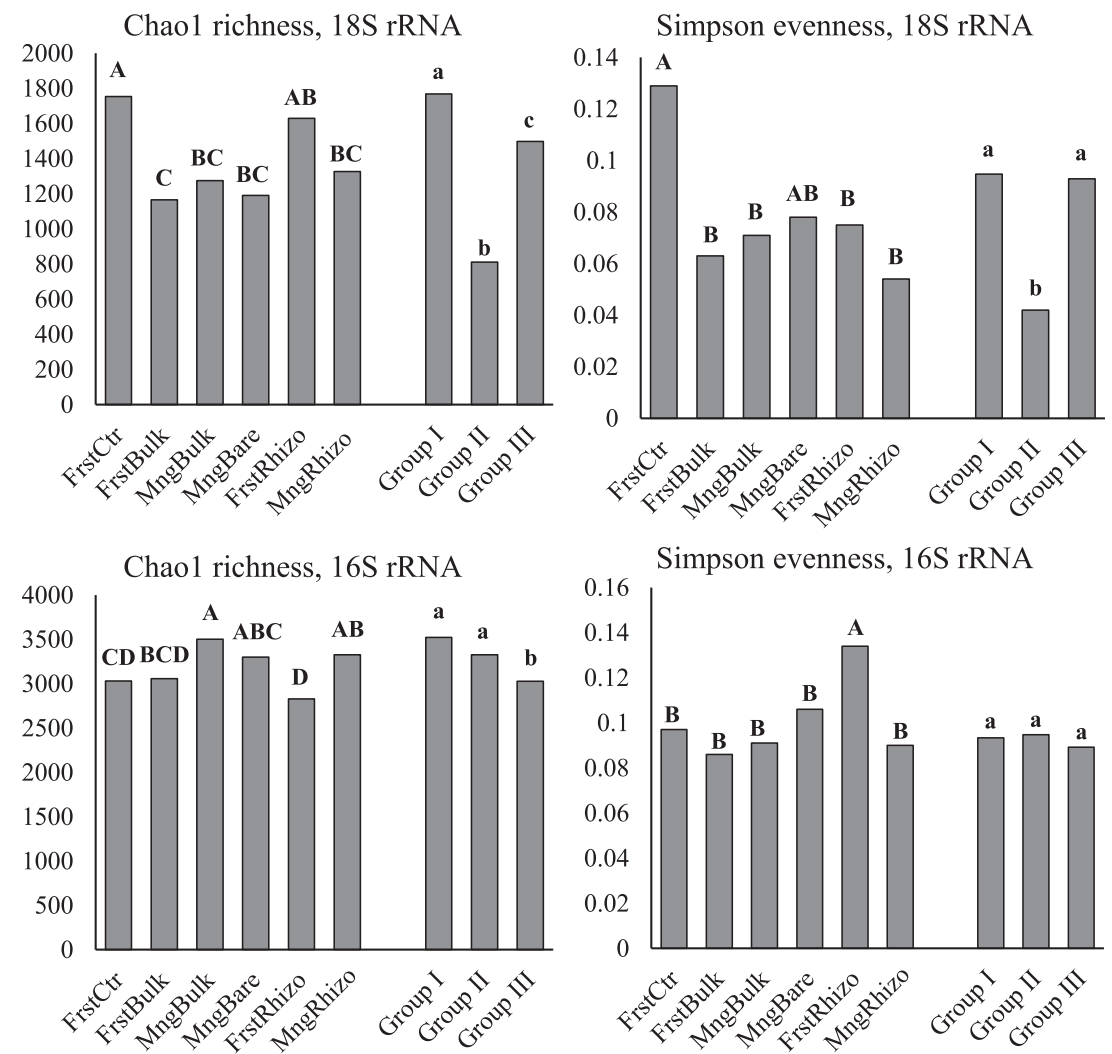

Fig. 2. Estimated total species richness (Chao1) and Simpson evenness. For each variable, data followed by different letters are significantly different according to Tukey's pairwise test $(P<0.05)$. Uppercase letters indicate differences between types of samples. Lowercase letters indicate differences between groups of sample sites based on locations. Group I and Group II - Microbial communities only from bulk soil (MngBulk) and bare spots (MngBare) from managed fields were included in the analysis. Group III - Microbial communities from FrstBulk and FrstCtr samples were included in the analysis. 
have demonstrated that soil $\mathrm{pH}$ could have an effect on fungal richness and diversity (Li et al. 2016; Siles and Margesin 2016; Wang et al. 2015; Wua et al. 2015). The relative abundances of Ascomycota and Mucoromycota were correlated with $\mathrm{pH}$ (Table 1). Six out of the top 15 most abundant eukaryotes exhibited significant differences in their relative abundances between FrstBulk and FrstCtr samples (Fig. 3A). Dinophyceae, Acantharea, Prymnesiophyceae, Telonemia, and Urochordata were relatively more abundant, while Ascomycota were relatively less abundant in FrstCtr samples compared with FrstBulk samples. Additionally, there was a significant increase in alpha-diversity of eukaryotic communities from FrstCtr compared with FrstBulk. The structure of bacterial communities did not differ between sample types $\left(R^{2}=0.04, P>0.05\right)$ (Table 2 ; Fig. 5B). In agreement with these data, no differences in bacterial relative abundances and alpha-diversity were detected between FrstBulk and FrstCtr (Fig. 2). However, bacterial diversity and relative abundances of several bacterial groups were correlated with $\mathrm{pH}$ and $\mathrm{Al}$ (Tables 1 and 4).
Overall, our data indicated that bacterial and eukaryotic communities differed in their responses to soil chemical properties. We detected only a weak correlation between the prokaryote and eukaryote weighted UniFrac distance matrices (Mantel test, $R=0.12$ and $P<0.001$ ). Combined effects of soil chemical properties, such as N, OM, and CEC, played a role in shaping eukaryotic communities. Higher relative abundances of fungi, Plantae/Embryophyceae, and Rhizaria/Filosa-Sarcomonadea, were associated with low fertility soils (low N, OM, and CEC, Group II fields), while higher relative abundances of Rhizaria/Acantharea, Alveolata/Dinophyceae, Hacrobia/Telonemia and Hacrobia/Prymnesiophyceae, and Metazoa/Urochordata, were associated with highly fertile soils (high N, OM, and CEC, Group I fields) (Table 1; Fig. 3). Additionally, high soil fertility was correlated with increased eukaryotic alpha-diversity (Table 4). On the other hand, bacterial alpha-diversity was less affected by soil fertility.

Differences between microbial communities from bulk and rhizosphere soil. MngBare and FrstCtr samples were excluded from beta-diversity distance matrices and the statistical significance

TABLE 3

Mean soil chemical characteristics ${ }^{y}$

\begin{tabular}{lccccccc}
\hline Factors/samples & FrstBulk & FrstCtr & MngBulk & MngBare & Group I & Group II & Group III \\
\hline pH $(\mathrm{pH}$ units) & $4.39 \mathrm{~B}$ & $4.65 \mathrm{~A}$ & $4.53 \mathrm{AB}$ & $4.48 \mathrm{AB}$ & $4.41 \mathrm{a}$ & $4.58 \mathrm{a}$ & $4.51 \mathrm{a}$ \\
\hline Nitrogen (total, \%) & $0.283 \mathrm{~A}$ & $0.180 \mathrm{~A}$ & $0.283 \mathrm{~A}$ & $0.212 \mathrm{~A}$ & $0.423 \mathrm{a}$ & $0.235 \mathrm{~b}$ & $0.235 \mathrm{~b}$ \\
\hline Organic matter $(\%)$ & $8.59 \mathrm{~A}$ & $5.32 \mathrm{~A}$ & $7.27 \mathrm{~A}$ & $5.30 \mathrm{~A}$ & $10.47 \mathrm{a}$ & $4.53 \mathrm{~b}$ & $7.10 \mathrm{ab}$ \\
\hline $\mathrm{CEC}^{\mathrm{z}}(\mathrm{meq} / 100 \mathrm{~g})$ & $7.35 \mathrm{~A}$ & $7.31 \mathrm{~A}$ & $7.81 \mathrm{~A}$ & $6.32 \mathrm{~A}$ & $9.19 \mathrm{a}$ & $6.34 \mathrm{~b}$ & $7.33 \mathrm{~b}$ \\
\hline Calcium $(\mathrm{kg} / \mathrm{ha})$ & $226 \mathrm{~A}$ & $189 \mathrm{~A}$ & $221 \mathrm{~A}$ & $42 \mathrm{~B}$ & $297 \mathrm{a}$ & $96.0 \mathrm{~b}$ & $209.4 \mathrm{a}$ \\
\hline $\mathrm{P}_{2} \mathrm{O}_{5}(\mathrm{~kg} / \mathrm{ha})$ & $108.3 \mathrm{~B}$ & $86.1 \mathrm{~B}$ & $249.1 \mathrm{~A}$ & $158.9 \mathrm{AB}$ & $419.2 \mathrm{a}$ & $110.2 \mathrm{~b}$ & $98.1 \mathrm{~b}$ \\
\hline $\mathrm{K}_{2} \mathrm{O}(\mathrm{kg} / \mathrm{ha})$ & $88.1 \mathrm{AB}$ & $74.8 \mathrm{~B}$ & $102.8 \mathrm{~A}$ & $45.9 \mathrm{~B}$ & $108 \mathrm{a}$ & $74.1 \mathrm{~b}$ & $82.1 \mathrm{~b}$ \\
\hline Sulfur $(\mathrm{kg} / \mathrm{ha})$ & $17.6 \mathrm{C}$ & $40.1 \mathrm{~B}$ & $51.1 \mathrm{~B}$ & $68.7 \mathrm{~A}$ & $46.7 \mathrm{a}$ & $61.7 \mathrm{~b}$ & $27.9 \mathrm{c}$ \\
\hline Magnesium $(\mathrm{kg} / \mathrm{ha})$ & $68.1 \mathrm{~A}$ & $41.37 \mathrm{~B}$ & $45.02 \mathrm{~B}$ & $11.93 \mathrm{C}$ & $57 \mathrm{a}$ & $23.1 \mathrm{~b}$ & $55.9 \mathrm{a}$ \\
\hline Aluminum $(\mathrm{ppm})$ & $1,296 \mathrm{~B}$ & $1,762 \mathrm{~A}$ & $1,762 \mathrm{~A}$ & $1,900 \mathrm{~A}$ & $1,688 \mathrm{ab}$ & $1,868 \mathrm{a}$ & $1,529 \mathrm{~b}$ \\
\hline Zinc $(\mathrm{ppm})$ & $2.61 \mathrm{~A}$ & $1.09 \mathrm{~B}$ & $2.61 \mathrm{~A}$ & $0.98 \mathrm{~B}$ & $2.87 \mathrm{a}$ & $1.39 \mathrm{~b}$ & $1.92 \mathrm{ab}$ \\
\hline Copper $(\mathrm{ppm})$ & $0.310 \mathrm{~A}$ & $0.274 \mathrm{~A}$ & $0.325 \mathrm{~A}$ & $0.444 \mathrm{~A}$ & $0.416 \mathrm{a}$ & $0.326 \mathrm{a}$ & $0.294 \mathrm{a}$ \\
\hline Iron $(\mathrm{ppm})$ & $188 \mathrm{~A}$ & $211 \mathrm{~A}$ & $205 \mathrm{~A}$ & $206 \mathrm{~A}$ & $206 \mathrm{a}$ & $205 \mathrm{a}$ & $199 \mathrm{a}$ \\
\hline Manganese $(\mathrm{ppm})$ & $15.4 \mathrm{~A}$ & $18.6 \mathrm{~A}$ & $19.9 \mathrm{~A}$ & $11.6 \mathrm{~A}$ & $23.57 \mathrm{a}$ & $14.09 \mathrm{a}$ & $16.91 \mathrm{a}$ \\
\hline
\end{tabular}

y For each variable, data followed by different letters are significantly different according to Tukey's test $(P<0.05)$. Uppercase letters indicate differences between types of samples. Lowercase letters indicate differences between groups of sample sites based on location.

z Cation exchange capacity.

TABLE 4

Correlation analysis considering eukaryote alpha-diversity and chemical soil factors ${ }^{z}$

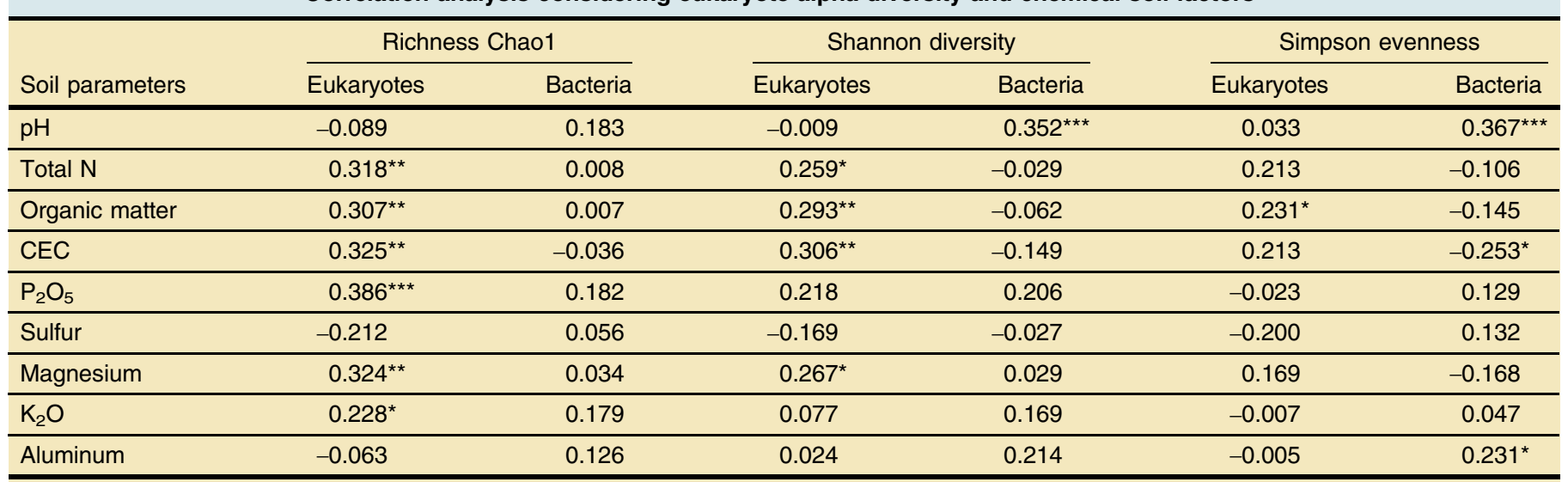

z Spearman's rank correlation test. Significance levels are shown at ${ }^{\star} P<0.05,{ }^{\star \star} P<0.01$, and ${ }^{\star \star \star} P<0.001$. 
of sample groupings into rhizosphere (MngRhizo and FrstRhizo) and bulk (MngBulk and FrstBulk) sample types was calculated. This analysis indicated that shifts from bulk to rhizosphere environments had little effect on soil eukaryotes $\left(R^{2}=0.03, P<0.05\right)$. However, it had much stronger effects on bacterial communities $\left(R^{2}=0.11, P<0.001\right)$ (Table 2). When samples were compared within each group, grouping of bacterial communities by rhizosphere and bulk types had more strength and statistical significance compared with the grouping of eukaryotic communities (Table 2). Considering taxonomic groups, the relative abundance of Ascomycota was significantly lower in the rhizosphere (Rhizo: MngRhizo and FrstRhizo) compared with bulk soils (Bulk: MngBulk and FrstBulk). However, the total number of reads annotated as Ascomycota classes producing ericoid mycorrhiza in temperate forest shrubs (Dothideomycetes, Lecanoromycetes, and Sordariomycetes) (Wurzburger et al. 2012) was similar between rhizosphere and bulk samples.

Out of the top 15 most abundant bacteria, the relative abundances of four bacterial classes, including Bacteroidetes, Actinobacteria, Alphaproteobacteria, and Gammaproteobacteria, were higher and the relative abundances of Acidobacteria DA052, Deltaproteobacteria, and candidate division ABS-6 were lower in plant rhizospheres. Additionally, in contrast to Alpha- and Gammaproteobacteria, which had significantly higher relative abundances in the plant rhizosphere, Deltaproteobacteria were much less abundant in the rhizosphere when compared with bulk soils. This suggests that wild blueberry does not stimulate proliferation of Deltaproteobacteria in the root environments. There is little evidence implicating this bacterial class in either beneficial or pathogenic interactions with plants. At the genus level, bacteria identified as Syntrophobacteraceae, Koribacteraceae, Chthoniobacter Da101 (Felske and Akkermans 1998), and Acidobacteria Da052 were enriched in bulk soils. Similar preferential presence of these bacteria in bulk soils was reported previously (Halsey et al. 2016; Hargreaves et al. 2015; Yarwood et al. 2013). Gammaproteobacteria/Dokdonella and nitrate-reducing Actinobacteria/Conexibacter (Seki et al. 2012) were significantly overrepresented in plant rhizospheres.

Effect of field management on soil and rhizosphere microbiome. Management was not a significant factor affecting bulk soil eukaryotic communities $\left(R^{2}=0.03, P>0.05\right)$ and had minor effect on rhizosphere eukaryotes $\left(R^{2}=0.07, P<0.05\right)$ (Table 2$)$. When statistical significance of fungal OTU sample grouping was tested, management also had a minor effect on fungal communities both in bulk $\left(R^{2}=0.05, P<\right.$ $0.05)$ and rhizosphere soils $\left(R^{2}=0.05, P<0.05\right)$. In agreement with this data, there were no differences in the relative abundances of eukaryotes detected between MngBulk and FrstBulk samples and only two eukaryotic classes, ringed worms (Annelid) and nematodes, were relatively more abundant in FrstRhizo compared with MngRhizo. Consistent with these findings, eukaryotic alpha-diversity was also not affected by management (Fig. 2).

Bacterial communities from natural and managed habitats diverged strongly from each other. Adonis analysis of the strength and statistical significance of sample groupings by management type showed significant effects of management on bulk soils $\left(R^{2}=\right.$ $0.12, P<0.001)$ and plant rhizospheres $\left(R^{2}=0.22, P<0.001\right)$ (Table 2). Communities from MngBulk and MngRhizo soils exhibited higher richness compared with FrstBulk and FrstRhizo
A

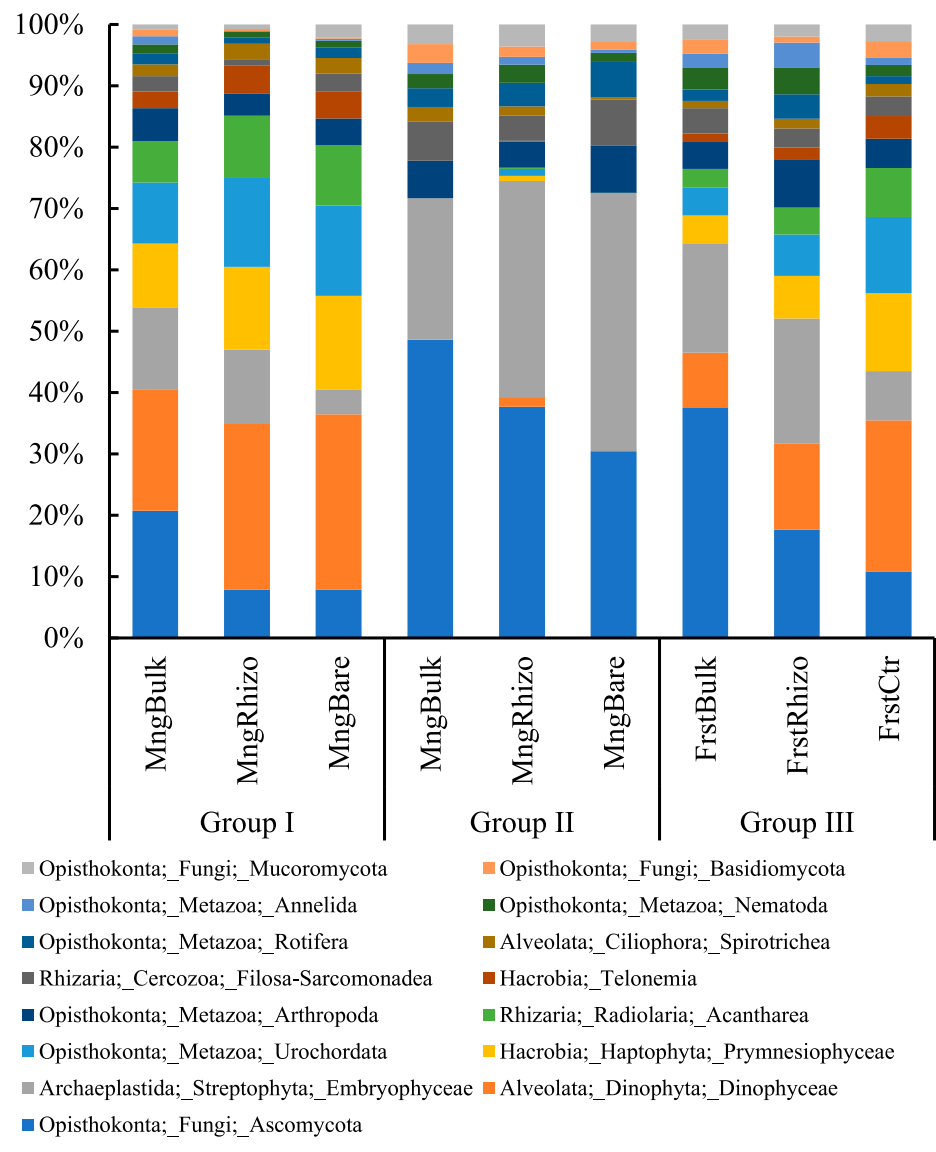

B

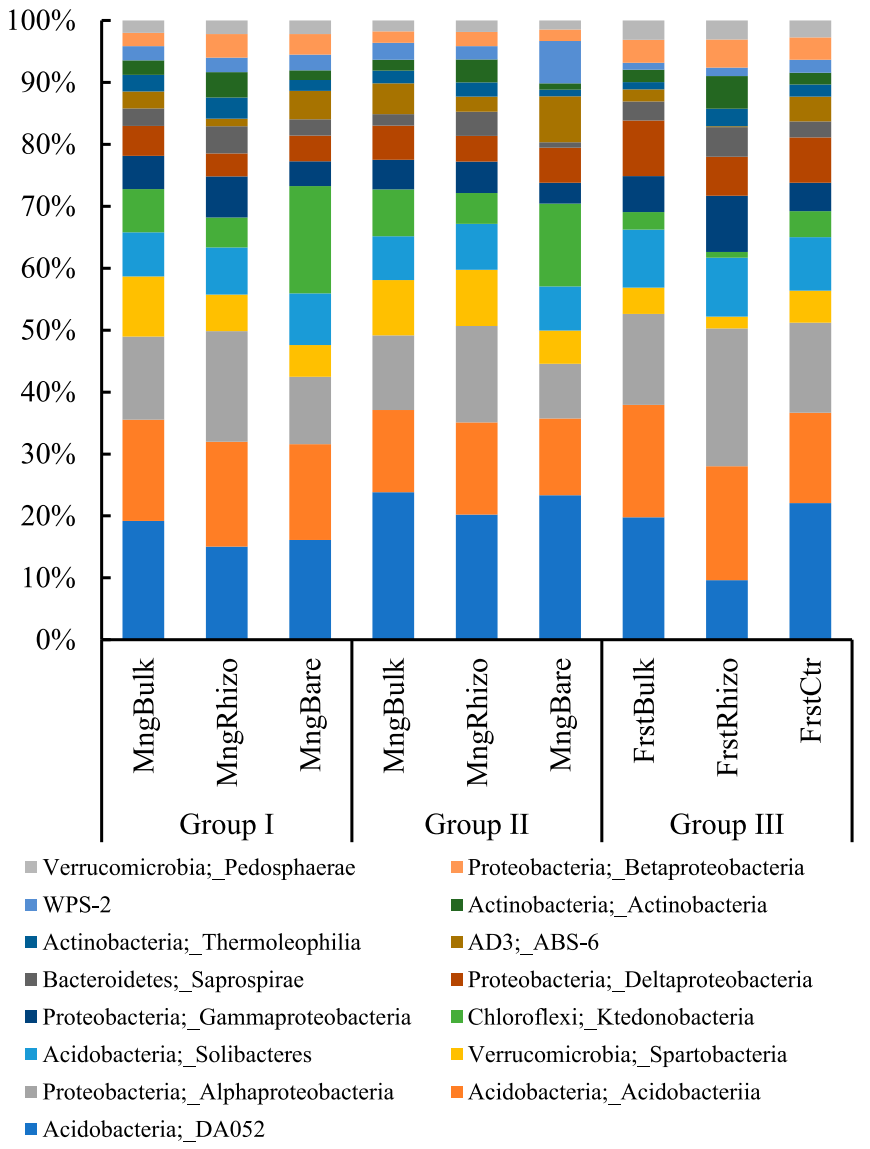

Fig. 3. Relative abundances of major microbial taxa present in the soil and rhizosphere microbial communities. A, Eukaryotes. B, Bacteria. 
soils, respectively; and eukaryotes from FrstRhizo were more even than MngRhizo microbiomes (Fig. 2). Out of the top 15 most abundant bacterial classes, 7 and 10 varied between MngBulk and FrstBulk and MngRhizo and FrstRhizo, respectively (Supplementary Fig. S7). Amounts of $\mathrm{P}_{2} \mathrm{O}_{5}$ and $\mathrm{Al}$ were increased in MngBulk compared with FrstBulk soils (Table 3) and the relative abundance of all the top 15 most abundant bacteria taxa were correlated with $\mathrm{P}_{2} \mathrm{O}_{5}$, or $\mathrm{Al}$, or both (Table 1), indicating a potential role of $\mathrm{P}_{2} \mathrm{O}_{5}$ and $\mathrm{Al}$ as factors affecting bacterial communities in blueberry bulk soils.

Increased relative abundances of Verrucomicrobia/Spartobacteria and Chloroflexi/Ktedonobacteria were observed in MngBulk compared with FrstBulk, while Verrucomicrobia/Pedosphaerae, Beta- and Deltaproteobacteria, Acidobacteria/Solibacteres, and candidate division WPS-2 were overrepresented in FrstBulk. Relative abundances of some of these bacterial classes, such as Pedosphaerae, Spartobacteria, Deltaproteobacteria, Ktedonobacteria, candidate divisions WPS-2, and Solibacteres were correlated in bulk and rhizosphere soils. However, Alphaproteobacteria/Bradyrhizobiaceae, IMethylocystaceae, /Caulobacteraceae, /Acetobacteraceae, and Gammaproteobacteria were relatively more abundant and Acidobacteria/DA052 and uncultured bacteria ABS-6 were relatively less abundant in rhizospheres of blueberry plants from forest habitats compared with those from managed fields, while their relative abundances were similar in both managed and native.

\section{DISCUSSION}

Management of commercial wild blueberry fields is one of a small number of examples where native plant habitats are moderately
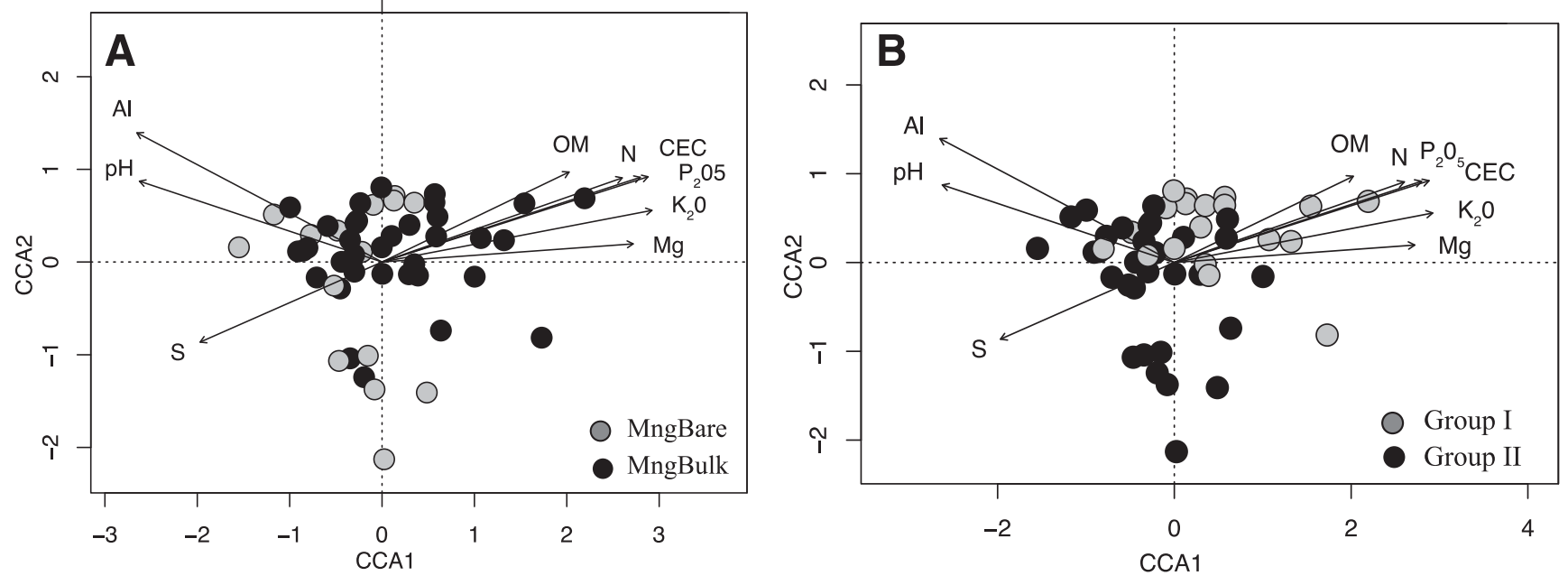

Fig. 4. Canonical correspondence analysis (CCA) used to determine which factors are linked to differences in bacterial OTUs across samples from managed fields. The rarified OTU table was used as input for the $16 \mathrm{~S}$ amplicon data. A, Samples were grouped by sample type: bulk soils (MngBulk) and bare spots (MngBare). B, Samples were grouped by field types: Group I and Group II fields. N, nitrogen; OM, organic matter; CEC, cationexchange capacity (number of exchangeable cations per dry weight of soil); $\mathrm{P}_{2} \mathrm{O}_{5}$, phosphate; $\mathrm{K}_{2} \mathrm{O}$, potassium; Mg, magnesium; $\mathrm{S}$, sulfur; and $\mathrm{Al}$, aluminum.
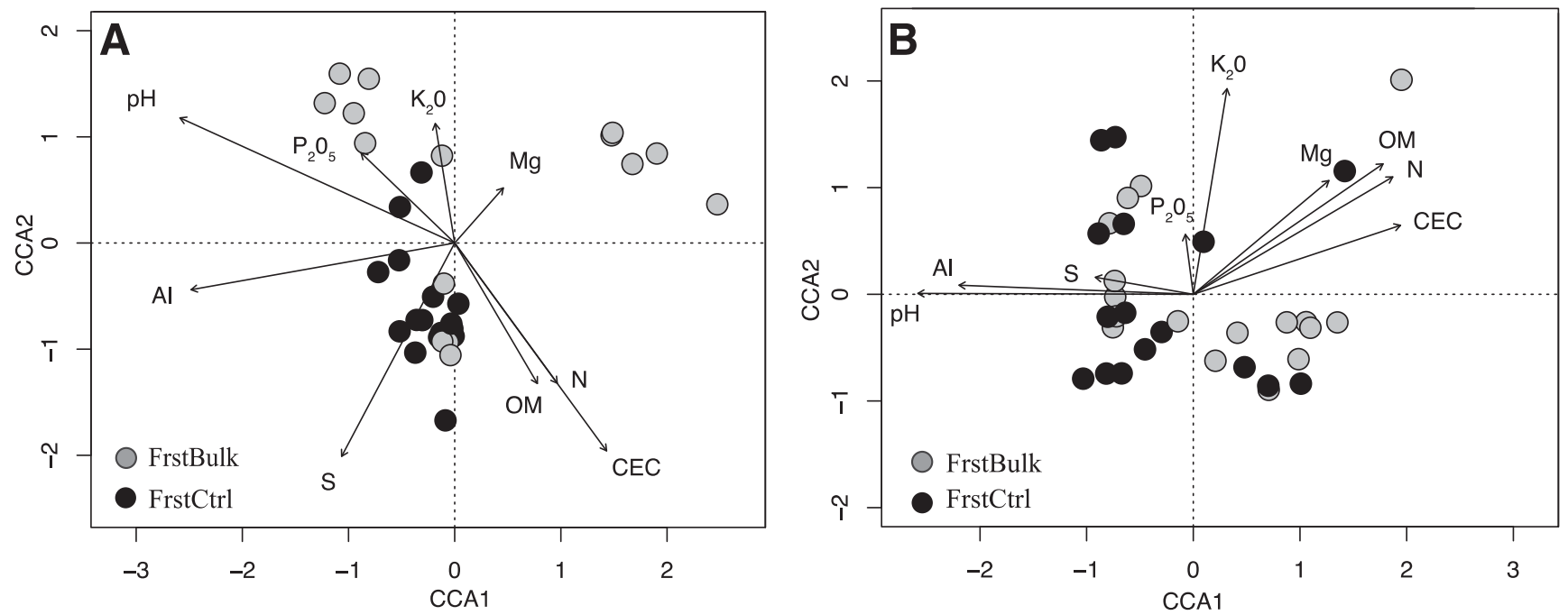

Fig. 5. Canonical correspondence analysis (CCA) used to determine which factors are linked to differences in microbial OTUs across samples from FrstBulk and FrstCtr samples from forest sites. The rarified OTU table was used as input for the A, 18S and B, 16S amplicon data. N, nitrogen; OM, organic matter; CEC, cation-exchange capacity (number of exchangeable cations per dry weight of soil); $\mathrm{P}_{2} \mathrm{O}_{5}$, phosphate; $\mathrm{K}_{2} \mathrm{O}$, potassium; Mg, magnesium; $\mathrm{S}$, sulfur; and $\mathrm{Al}$, aluminum. 
modified to improve fruit yield and facilitate harvest (Bell et al. 2009; Drummond et al. 2009; Eaton 1988; Hall et al. 1979). The effect of land-use on soil microbiomes has been previously studied (Mendes et al. 2015; Sarrantonio and Gallandt 2003) in other contexts. In contrast to those studies, where the use of the land implied an introduction of exogenous plant species as part of an agricultural system, we evaluated the effect of managing the land to promote production of endemic plants on changes to the soil microbiome. We incorporated high replications and several locations of sampling sites to apply statistical analysis of the data and evaluated natural and managed wild blueberry habitats, including soil and rhizosphereassociated microbiomes. The analysis of both bacterial and eukaryotic communities provided a better understanding of how soil bacterial and eukaryotic communities differ in their responses to biotic and abiotic factors. We also addressed the question of how the changes in land-use affect plant-associated microbiomes.

All microbial abundances reported in this study are relative and not absolute, a limitation for most $16 \mathrm{~S} / 18 \mathrm{~S}$ microbiome studies. In agreement with current knowledge of the composition of bacterial communities in soils (Bulgarelli et al. 2013; Fierer et al. 2009; Foulon et al. 2016; Shi et al. 2015), Acidobacteria, Actinobacteria, Proteobacteria, Chloroflexi, and Bacteroidetes were the most relatively abundant bacterial phyla detected across all wild blueberry samples. Similar to our data, several reports found that Ascomycota was the most relatively abundant fungal phylum in soil (MorrisonWhittle and Goddard 2015; Noyce et al. 2016; Orgiazzi et al. 2012; Zhou et al. 2017). Based on 18S sequencing, between 75 and $84 \%$ of the total eukaryotic community was represented by fungi in forest biochar microbiomes (Morrison-Whittle and Goddard 2015; Noyce et al. 2016) compared with about $23 \%$ of fungal OTUs identified in wild blueberry microbiomes. This difference could be due to a simple technical aspect of different primer sets having different affinities/biases for the taxonomic groups, or this could be caused by true environmental differences in microbial habitats. Our data indicating significant differences in the relative abundances of fungi between soils with high and low fertility (Group I and Group II fields) and between soil with different $\mathrm{pH}, \mathrm{S}, \mathrm{Mg}, \mathrm{Al}$, and $\mathrm{Z}$ (FrstBulk and FrstCtr) support this conclusion (Table 3; Fig. 3).

Hacrobia/Prymnesiophyceae, Hacrobia/Telonemia, Metazoa/ Urochordata, and Rhizaria/Acantharea were among the 15 most relatively abundant soil eukaryotes identified in our study. These eukaryotes have not been reported in soils, but have been associated with aquatic environments. In conjunction with previously published reports on the presence in soils of single-celled eukaryotes considered to be typical for marine ecosystems (Bates et al. 2013; Coolen et al. 2011; Dupont et al. 2016; Lejzerowicz et al. 2010), these results suggest that a much broader spectrum of eukaryotic taxa can occupy terrestrial environments and these terrestrial eukaryotes have simply not been detected before due to the limited number of nonfungal eukaryote molecular studies in soil, although the low $\mathrm{pH}$ character of blueberry habitat may have contributed to their detection here.

The goal of our sampling strategy was to analyze microbial communities from diverse soil environments, plant growth conditions (natural and managed habitats, plant pruning, soil amendments, and vegetation cover) and locations (about $100 \mathrm{~km}$ range), which were linked together by association with $V$. angustifolium. Due to the ability of the host plant to modify root-associated environments, soil physiochemical properties could be different between rhizosphere and bulk soil. In this study, only the chemical characteristics of bulk soils were analyzed. Comparison of bulk soil microbial communities allowed us to evaluate the correlation between soil chemical composition and community profiles. We showed that composition and structure of bulk eukaryotes were more strongly correlated with soil fertility (N, OM, and CEC) compared with the composition and structure of bacterial communities. These data are in agreement with the previous reports showing that soil fertility had a strong effect on soil eukaryotes (Lentendu et al. 2014; Shen et al. 2014; Wang et al. 2015), while overall bacterial diversity was not strongly affected by soil fertility (Wang et al. 2016).

One possible factor that could affect the structure of bacterial communities is soil temperature. We measured soil temperature during sampling and found that, because of the absence of vegetation in MngBare, on sunny days and depending on the time of the day, the soil temperature could be up to $7^{\circ} \mathrm{C}$ higher than MngRhizo (data not shown). The increase in relative abundance of Ktedonobacteria, which has a higher temperature tolerance, in MngBare compared with MngBulk supports this suggestion. Additionally, Gammaproteobacteria were relatively less abundant in MngBare than in MngBulk, which was in agreement with the report of negative effect of increasing temperature on the relative abundance of Gammaproteobacteria (Siles and Margesin 2016; Wua et al. 2015).

We compared the composite microbial profiles from bulk (MngBulk and FrstBulk, $\sim 50$ samples total) and rhizosphere (MngRhizo and FrstRhizo, $\sim 50$ samples total) soils across several locations, natural and managed wild blueberry habitats, and bulk soils with different fertility (OM, N, and CEC) and macro- and micronutrient content. By examining these environmental variables, we could identify differences between rhizosphere and bulk microbial communities that were relatively environment-independent and may better reflect fundamental principles that shape wild blueberry root microbiomes. It is well documented that root and soil bacterial communities diverge significantly and the major population shifts between these two niches reflect an increase in relative abundances in bacterial phyla including Alpha-, Beta-, and Gammaproteobacteria, Bacteroidetes, and Actinobacteria (Bulgarelli et al. 2013; Hargreaves et al. 2015; Mao et al. 2014). In agreement with this notion, an increase in relative abundances of these bacterial phyla was detected in wild blueberry rhizospheres. Additionally, and for the first time, the accumulation of Dokdonella and Conexibacter was documented in plant rhizospheres. Dokdonella has been recently isolated from soils and was shown to be part of alkane, $\mathrm{N}_{2} \mathrm{O}$, and polycyclic aromatic hydrocarbon biodegradation communities. It can also cause bacteremia in immunocompromised people (Alonso-Gutierrez et al. 2009; Bacosa and Inoue 2015; Lee and Weinstein 2014; Ten et al. 2009; Yoon et al. 2006). Our data also indicated that the shift from bulk to rhizosphere niche had much stronger effects on composition and structure of bacterial communities compared with that of eukaryotic communities. Previously, it was reported that eukaryotic and bacterial communities exhibit different global-scale biogeographical patterns (Bates et al. 2013). Our data indicated that these two types of communities also respond differently to local soil properties and niches in wild blueberry production settings.

A second question we addressed was to determine how management of blueberry habitat affected bulk soil and rhizosphere microbiomes. Based on our evaluation of bacterial alpha-diversity, the statistical significance of sample groupings, and community comparison, we can conclude that the aggregate difference in forest versus managed systems influenced bacterial communities in blueberry rhizospheres, but had less effect on eukaryotic communities. The bulk soil microbiome serves as a foundation for rootassociated microbial communities. Therefore, a high relative abundance of a microbial group in the rhizosphere might be directly linked to its high abundance in bulk soil, while the enrichment of a microbial group in rhizosphere compared with bulk soils might better reflect plant-derived factors shaping development of a root microbiome. For example, Alpha- and Gammaproteobacteria were relatively more abundant in rhizospheres of plants from natural 
habitats. The members of these bacterial classes have a high capacity to utilize root exudates for growth (Lareen et al. 2016; Mao et al. 2014; Reinhold-Hurek et al. 2015) and therefore might respond to the plant-derived changes in the rhizosphere environment.

Host plant factors play a role in determining the composition of root-associated microbial communities. In addition to the genotype of the host, developmental stage, its nutrient requirements, and adaptation to stresses could define the strength and specificity of plant selection (Lareen et al. 2016). The blueberry is a long-lived shrub (>200 years) (Bell et al. 2009; Drummond et al. 2009; Hall et al. 1979) that can reproduce through an extensive underground rhizome system. The production fields sampled in this study were developed over at least 30 years ago by removing competing weeds, which facilitated the vegetative expansion of the existing blueberry plants and allowed the blueberries to entirely colonize these fields. We also ensured that blueberry plants from natural habitats were mature and well established. In our experiment, we chose fields that were in the second year of a growth-crop production year cycle. However, because of previous pruning, use of soil applied fertilizers and pest management practices, the plants in the managed stands had much higher growth rates and fruit production than forest stands. These management differences result in berry yields that range from 500 to $1,000 \mathrm{~kg} \cdot \mathrm{ha}^{-1}$ in unmanaged stands to commercial fields yielding in excess of $6,000 \mathrm{~kg} \cdot \mathrm{ha}^{-1}$, with some commercial fields producing in excess of $12,000 \mathrm{~kg} \cdot \mathrm{ha}^{-1}$.

Conclusion. Because of the specificity of production management, $V$. angustifolium phytobiome provides a unique system to analyze the effects of biotic and abiotic factors on diversity and structure of soil- and plant-associated microbial communities in natural and agricultural ecosystems. Our data also indicate that soil bacterial and eukaryotic microbiomes respond differently to biotic and abiotic factors: soil eukaryotes are more affected by soil chemical characteristics, while bacteria are more affected by the presence of the plant. This suggests that inclusion of both eukaryotic and bacterial microbiomes in the analysis of community composition could bring new insight into complex plant-microbiome interactions and the environment. Additionally, comprehensive surveys of soil biodiversity allowed us to identify several eukaryotic groups that had previously been associated with marine ecosystems, suggesting a much broader spectrum of terrestrial eukaryotic taxa than generally recognized. In addition to an extension of our basic knowledge of the response of bacterial and eukaryotic communities to biotic and abiotic factors, the data presented in this study could provide a baseline for evaluation of the effect of management on wild blueberry environmental conditions in a variety of agricultural settings including different crop production cycle schemes and soil amendment applications.

\section{ACKNOWLEDGMENTS}

This work was supported by Nova Scotia Research Acceleration grants RA2016-005 and RA2015-005, Natural Sciences and Engineering Research Council of Canada grant EGP 485260, NSERC Discovery Grant, Wild Blueberry Producers Association of Nova Scotia, and Bragg Lumber Company to S. N. Yurgel. Additional support was provided to M. G. I. Langille through the Strategic Research Initiatives Fund from Dalhousie University and a Discovery Grant from the Natural Sciences and Engineering Research Council of Canada. We thank M. Kahn (WSU) for reading this manuscript and providing useful comments.

\section{LITERATURE CITED}

Alonso-Gutierrez, J., Figueras, A., Albaiges, J., Jimenez, N., Vinas, M., Solanas, A. M., and Novao, B. 2009. Bacterial communities from shoreline environments (costa da morte, northwestern Spain) affected by the Prestige oil spill. Appl. Environ. Microbiol. 75:3407-3418.

Bacosa, H. P., and Inoue, C. 2015. Polycyclic aromatic hydrocarbons (PAHs) biodegradation potential and diversity of microbial consortia enriched from tsunami sediments in Miyagi, Japan. J. Hazard. Mater. 283:689-697.

Bates, S. T., Clemente, J. C., Flores, G. E., Walters, W. A., Parfrey, L. W., Knight, R., and Fierer, N. 2013. Global biogeography of highly diverse protistan communities in soil. ISME J. 7:652-659.

Bell, D. J., Rowland, L. J., Zhang, D., and Drummonda, F. A. 2009. Spatial genetic structure of lowbush blueberry, Vaccinium angustifolium, in four fields in Maine. Botany 87:932-946.

Berendsen, R. L., Pieterse, C. M., and Bakker, P. A. 2012. The rhizosphere microbiome and plant health. Trends Plant Sci. 17:478-486.

Bulgarelli, D., Schlaeppi, K., Spaepen, S., Ver Loren van Themaat, E., and Schulze-Lefert, P. 2013. Structure and functions of the bacterial microbiota of plants. Annu. Rev. Plant Biol. 64:807-838.

Bushnell, B. 2014. BBMap: A Fast, Accurate, Splice-Aware Aligner. Report Number LBNL-7065E.

Caporaso, J. G., Kuczynski, J., Stombaugh, J., Bittinger, K., Bushman, F. D., Costello, E. K., Fierer, N., Pena, A. G., Goodrich, J. K., Gordon, J. I., Huttley, G. A., Kelley, S. T., Knights, D., Koenig, J. E., Ley, R. E., Lozupone, C. A., McDonald, D., Muegge, B. D., Pirrung, M., Reeder, J., Sevinsky, J. R., Turnbaugh, P. J., Walters, W. A., Widman, J., Yatsunenko, T., Zaneveld, J., and Knight, R. 2010. QIIME allows analysis of high-throughput community sequencing data. Nat. Methods 7:335-336.

Caron, D. A., Countway, P. D., Jones, A. C., Kim, D. Y., and Schnetzer, A. 2012. Marine protistan diversity. Annu. Rev. Mar. Sci. 4:467-493.

Chaparro, J. M., Badri, D. V., and Vivanco, J. M. 2014. Rhizosphere microbiome assemblage is affected by plant development. ISME J. 8:790-803.

Comeau, A. M., Douglas, G. M., and Langille, M. G. 2017. Microbiome Helper: A custom and streamlined workflow for microbiome research. mSystems 2:e00127-16.

Coolen, M. J., van de Giessen, J., Zhu, E. Y., and Wuchter, C. 2011. Bioavailability of soil organic matter and microbial community dynamics upon permafrost thaw. Environ. Microbiol. 13:2299-2314.

Donn, S., Kirkegaard, J. A., Perera, G., Richardson, A. E., and Watt, M. 2015. Evolution of bacterial communities in the wheat crop rhizosphere. Environ. Microbiol. 17:610-621.

Drummond, F., Smagula, J., Annis, S., and Yarborough, D. 2009. Organic wild blueberry production. Maine Agricultural and Forest Experiment Station Bulletin 852.

Dupont, A. O., Griffiths, R. I., Bell, T., and Bass, D. 2016. Differences in soil micro-eukaryotic communities over soil $\mathrm{pH}$ gradients are strongly driven by parasites and saprotrophs. Environ. Microbiol. 18:2010-2024.

Eaton, L. J. 1988. Nutrient Cycling in Lowbush Blueberries. Dalhousie University, Bible Hill, Nova Scotia.

Edgar, R. C., Haas, B. J., Clemente, J. C., Quince, C., and Knight, R. 2011. UCHIME improves sensitivity and speed of chimera detection. Bioinformatics 27:2194-2200.

Felske, A., and Akkermans, A. D. 1998. Prominent occurrence of ribosomes from an uncultured bacterium of the Verrucomicrobiales cluster in grassland soils. Lett. Appl. Microbiol. 26:219-223.

Fierer, N., Strickland, M. S., Liptzin, D., Bradford, M. A., and Cleveland, C. C. 2009. Global patterns in belowground communities. Ecol. Lett. 12:1238-1249.

Fisher, C. K., and Mehta, P. 2014. The transition between the niche and neutral regimes in ecology. Proc. Natl. Acad. Sci. USA 111:13111-13116.

Foulon, J., Zappelini, C., Durand, A., Valot, B., Blaudez, D., and Chalot, M. 2016. Impact of poplar-based phytomanagement on soil properties and microbial communities in a metal-contaminated site. FEMS Microbiol. Ecol. 92:fiw163.

Goldin, A. 1987. Reassessing the use of loss-on-ignition for estimating organic matter content in noncalcareous soils. Commun. Soil Sci. Plant Anal. 18:1111-1116.

Gordon, A., and Hannon, G. (2010). FASTX-Toolkit: FASTQ/A short-reads preprocessing tools. http://hannonlab.cshl.edu/fastx_toolkit.

Goulart, B. L., Schroeder, M. L., Demchak, K., Lynch, J. P., Clark, J. R., Darnell, R. L., and Wilcox, W. F. 1993. Blueberry mycorrhizae: Current knowledge and future directions. Acta Hortic. 346:230-239.

Hall, I. V., Aalders, L. E., Nickerson, N. L., and Vander Kloet, S. P. 1979. The biological flora of Canada. I. Vaccinium angustifolium Ait. sweet lowbush blueberry. Can. Field Nat. 93:415-430.

Halsey, J. A., de Cassia Pereira, E. S. M., and Andreote, F. D. 2016. Bacterial selection by mycospheres of Atlantic Rainforest mushrooms. Antonie van Leeuwenhoek 109:1353-1365.

Hammer, Ø., Harper, D. A. T., and Ryan, P. D. 2001. PAST: Paleontological statistics software package for education and data analysis. Palaeontologia Electronica 4:9. 
Hargreaves, S. K., Williams, R. J., and Hofmockel, K. S. 2015. Environmental filtering of microbial communities in agricultural soil shifts with crop growth. PLoS One 10:e0134345.

Jeliazkova, E., and Percival, D. 2002. Effect of drought on ericoid mycorrhizae in wild blueberry (Vaccinium angustifolium Ait.). Can. J. Plant Sci. 83: 583-586.

Kopylova, E., Noe, L., and Touzet, H. 2012. SortMeRNA: Fast and accurate filtering of ribosomal RNAs in metatranscriptomic data. Bioinformatics 28:3211-3217.

Korcak, R. F. 1989. Variation in nutrient requirements of blueberries and other calcifuges. HortScience 24:573-578.

Lapsansky, E. R., Milroy, A. M., Andales, M. J., and Vivanco, J. M. 2016. Soil memory as a potential mechanism for encouraging sustainable plant health and productivity. Curr. Opin. Biotechnol. 38:137-142.

Lareen, A., Burton, F., and Schafer, P. 2016. Plant root-microbe communication in shaping root microbiomes. Plant Mol. Biol. 90:575-587.

Lee, B., and Weinstein, M. R. 2014. Dokdonella koreensis bacteremia: A case report and review of the literature. Can. J. Infect. Dis. Med. Microbiol. 25:255-256.

Lejzerowicz, F., Pawlowski, J., Fraissinet-Tachet, L., and Marmeisse, R. 2010. Molecular evidence for widespread occurrence of Foraminifera in soils. Environ. Microbiol. 12:2518-2526.

Lentendu, G., Wubet, T., Chatzinotas, A., Wilhelm, C., Buscot, F., and Schlegel, M. 2014. Effects of long-term differential fertilization on eukaryotic microbial communities in an arable soil: a multiple barcoding approach. Mol. Ecol. 23:3341-3355.

Li, G., Xu, G., Shen, C., Tang, Y., Zhang, Y., and Ma, K. 2016. Contrasting elevational diversity patterns for soil bacteria between two ecosystems divided by the treeline. Sci. China Life Sci. 59:1177-1186.

Lozupone, C., Lladser, M. E., Knights, D., Stombaugh, J., and Knight, R. 2011. UniFrac: An effective distance metric for microbial community comparison. ISME J. 5:169-172.

Maignien, L., DeForce, E. A., Chafee, M. E., Eren, A. M., and Simmons, S. L. 2014. Ecological succession and stochastic variation in the assembly of Arabidopsis thaliana phyllosphere communities. MBio 5:e0682-13.

Mao, Y., Li, X., Smyth, E. M., Yannarell, A. C., and Mackie, R. I. 2014. Enrichment of specific bacterial and eukaryotic microbes in the rhizosphere of switchgrass (Panicum virgatum L.) through root exudates. Environ. Microbiol. Rep. 6:293-306.

Mehlich, A. 1984. Mehlich 3 soil test extractant: A modification of Mehlich 2 extractant. Commun. Soil Sci. Plant Anal. 15:1409-1416.

Mendes, L. W., Tsai, S. M., Navarrete, A. A., de Hollander, M., van Veen, J. A., and Kuramae, E. E. 2015. Soil-borne microbiome: Linking diversity to function. Microbiol. Ecol. 70:255-265.

Mercier, C., Boyer, F., Bonin, A., and Coissac, E. 2013. SUMATRA and SUMACLUST: Fast and exact comparison and clustering of sequences. https://git.metabarcoding.org/obitools/sumatra/wikis/home

Micallef, S. A., Channer, S., Shiaris, M. P., and Colon-Carmona, A. 2009a. Plant age and genotype impact the progression of bacterial community succession in the Arabidopsis rhizosphere. Plant Signal. Behav. 4:777-780.

Micallef, S. A., Shiaris, M. P., and Colon-Carmona, A. 2009b. Influence of Arabidopsis thaliana accessions on rhizobacterial communities and natural variation in root exudates. J. Exp. Bot. 60:1729-1742.

Morrison-Whittle, P., and Goddard, M. R. 2015. Quantifying the relative roles of selective and neutral processes in defining eukaryotic microbial communities. ISME J. 9:2003-2011.

Noyce, G. L., Winsborough, C., Fulthorpe, R., and Basiliko, N. 2016. The microbiomes and metagenomes of forest biochars. Sci. Rep. 6:26425.

Oksanen, J., Blanchet, F. G., Friendly, M., Kindt, R., Legendre, P., and McGlinn, D. 2016. Vegan: Community Ecology Package. R package version 2.4-0. https://cran.r-project.org/web/packages/vegan/index.html

Orgiazzi, A., Lumini, E., Nilsson, R. H., Girlanda, M., Vizzini, A., Bonfante, P., and Bianciotto, V. 2012. Unravelling soil fungal communities from different Mediterranean land-use backgrounds. PLoS One 7:e34847.

Panke-Buisse, K., Poole, A. C., Goodrich, J. K., Ley, R. E., and Kao-Kniffin, J. 2015. Selection on soil microbiomes reveals reproducible impacts on plant function. ISME J. 9:980-989.

Parks, D. H., Tyson, G. W., Hugenholtz, P., and Beiko, R. G. 2014. STAMP: Statistical analysis of taxonomic and functional profiles. Bioinformatics 30:3123-3124.

Percival, D. C., and Privé, J. P. 2002. Nitrogen formulation influences plant nutrition and yield components of lowbush blueberry (Vaccinium angustifolium Ait.). Acta Hortic. 574:301-311.
Philippot, L., Raaijmakers, J. M., Lemanceau, P., and van der Putten, W. H. 2013. Going back to the roots: the microbial ecology of the rhizosphere. Nat. Rev. Microbiol. 11:789-799.

Quadros, P., Zhalnina, Z., Davis-Richardson, A., Fagen, J., Drew, J., Bayer, C. 2012. The effect of tillage system and crop rotation on soil microbial diversity and composition in a subtropical acrisol. Diversity (Basel) 4: 375-395.

Read, D. J. 1983. The biology of mycorrhiza in the Ericales. Can. J. Bot. 61:985-1004.

Reinhold-Hurek, B., Bunger, W., Burbano, C. S., Sabale, M., and Hurek, T. 2015. Roots shaping their microbiome: Global hotspots for microbial activity. Annu. Rev. Phytopathol. 53:403-424.

Sarrantonio, M., and Gallandt, E. 2003. The role of cover crops in North American cropping systems. J. Crop Prod. 8:53-74.

Seki, T., Matsumoto, A., Shimada, R., Inahashi, Y., Omura, S., and Takahashi, Y. 2012. Conexibacter arvalis sp. nov., isolated from a cultivated field soil sample. Int. J. Syst. Evol. Microbiol. 62:2400-2404.

Shen, C., Liang, W., Shi, Y., Lin, X., Zhang, H., Wu, X., Xie, G., Chain, P., Grogan, P., and Chu, H. 2014. Contrasting elevational diversity patterns between eukaryotic soil microbes and plants. Ecology 95:3190-3202.

Shi, Y., Xiang, X., Shen, C., Chu, H., Neufeld, J. D., Walker, V. K., and Grogan, P. 2015. Vegetation-associated impacts on arctic tundra bacterial and microeukaryotic communities. Appl. Environ. Microbiol. 81:492-501.

Siles, J. A., and Margesin, R. 2016. Abundance and diversity of bacterial, archaeal, and fungal communities along an altitudinal gradient in alpine forest soils: What are the driving factors? Microbiol. Ecol. 72:207-220.

Ten, L. N., Jung, H. M., Im, W. T., Oh, H. W., Yang, D. C., Yoo, S. A., and Lee, S.-T. 2009. Dokdonella ginsengisoli sp. nov., isolated from soil from a ginseng field, and emended description of the genus Dokdonella. Int. J. Syst. Evol. Microbiol. 59:1947-1952.

Tkacz, A., Cheema, J., Chandra, G., Grant, A., and Poole, P. S. 2015. Stability and succession of the rhizosphere microbiota depends upon plant type and soil composition. ISME J. 9:2349-2359.

van der Heijden, M. G., Martin, F. M., Selosse, M. A., and Sanders, I. R. 2015. Mycorrhizal ecology and evolution: the past, the present, and the future. New Phytol. 205:1406-1423.

Wang, J., Xue, C., Song, Y., Wang, L., Huang, Q., and Shen, Q. 2016. Wheat and rice growth stages and fertilization regimes alter soil bacterial community structure, but not diversity. Front. Microbiol. 7:1207.

Wang, J. T., Zheng, Y. M., Hu, H. W., Zhang, L. M., Li, J., and He, J. Z. 2015. Soil $\mathrm{pH}$ determines the alpha diversity but not beta diversity of soil fungal community along altitude in a typical Tibetan forest ecosystem. J. Soils Sediments 15:1224-1232.

Wilson, J. 1908. Domestication of the blueberry. Pages 61-62 in: USDA Yearbook of Agriculture. USDA, Washington, DC.

Wua, J., Xionga, J., Hua, C., Shib, Y., Wanga, K., and Zhanga, D. 2015. Temperature sensitivity of soil bacterial community along contrasting warming gradient. Appl. Soil Ecol. 94.

Wurzburger, N., Higgins, B. P., and Hendrick, R. L. 2012. Ericoid mycorrhizal root fungi and their multicopper oxidases from a temperate forest shrub. Ecol. Evol. 2:65-79.

Yarwood, S., Brewer, E., Yarwood, R., Lajtha, K., and Myrold, D. 2013. Soil microbe active community composition and capability of responding to litter addition after 12 years of no inputs. Appl. Environ. Microbiol. 79:1385-1392.

Yoon, J. H., Kang, S. J., and Oh, T. K. 2006. Dokdonella koreensis gen. nov., sp. nov., isolated from soil. Int. J. Syst. Evol. Microbiol. 56:145-150.

Zhang, J., Kobert, K., Flouri, T., and Stamatakis, A. 2014a. PEAR: A fast and accurate Illumina Paired-End reAd mergeR. Bioinformatics 30:614-620.

Zhang, Y., Xu, J., Dong, F., Liu, X., Wu, X., and Zheng, Y. 2014b. Response of microbial community to a new fungicide fluopyram in the silty-loam agricultural soil. Ecotoxicol. Environ. Saf. 108:273-280.

Zhou, Z. F., Wang, M. X., Zuo, X. H., and Yao, Y. H. 2017. Comparative investigation of bacterial, fungal, and archaeal community structures in soils in a typical oilfield in Jianghan, China. Arch. Environ. Contam. Toxicol. 72:65-77.

\section{AUTHOR-RECOMMENDED INTERNET RESOURCE}

The University of Maine:

https://extension.umaine.edu/blueberries/factsheets/production/improving-yourwild-blueberry-yields/ 